\title{
Let's Talk about Oral Health - Because it Matters in Global Health Aspect
}

\author{
Dr.Soumalya Ghosh ${ }^{1}$, Dr. Amini Ndisanze ${ }^{2}$ \\ ${ }^{1}$ Center for Public Health, National Institute of Mental Health and Neurosciences, Bangalore, India \\ ${ }^{2}$ University of Rwanda, College of Medicine and Health Sciences, School of Dentistry, Rwanda
}

\begin{abstract}
Oral Health is the most neglected area in global health prospect. Most of the people in the world are confused about oral disease with illness. Oral diseases are still a global burden, despite the improvement in some developed countries. It used to be mostly developed countries having high rate of dental caries and oro-esophageal cancer due to high sugar consumption and smoking. The oral health is neglected in health systems repartition health expenditures. There are diverse oral disease in the world like dental caries, periodontal diseases, tooth loss, oral and mucosal lesion, oral cancers, dental trauma and HIV/AIDS related diseases all this are major global health issues and poor oral health has a significant effect to the general health of the individual and the quality of life. Across the globe oral diseases burden trend reflects the difference in oral health awareness and public health programs, risk factors and environmental factors, the unhealthy lifestyles like poor oral hygiene, unhealthy diet, high tobacco consumption and alcohol drinking. Road traffic accident and sports injury are the main risk factors for the orofacial trauma. Social determinants of health and risk factors integration in oral health with global health programs is of high importance. Global emphasis on Community level oral health programs on implementing oral health policy, promotions and prevention are the urgent needs.
\end{abstract}

Keywords: Dental, Oral Health, Global Health, Oral Cancer, Dental Expenditure

\section{Introduction}

"Some tortures are 'physical' and some are 'mental', But the one that is both, is 'Dental"'

We know that tooth structure is the hardest structure of human body. Everybody on the planet from everyday life we can hear somebody's companion or somebody's relative is experiencing a toothache. Generally, in most of the countries, people endure the pain up to the stage of the terribly decayed tooth.

A toothache just a common example of dental health, there are hundreds of dental health problems are there in the world which are essential to general health and quality of life. Solid dental Health implies, a state of being liberate from mouth and facial pain, oral, and throat cancer, oral infection and sores, periodontal (gum) disease, tooth decay, tooth loss, and other diseases and disorders that limit an individual's capacity in biting, masticating, smiling, verbalizing, and psychosocial salubrity.

Globally $60-90 \%$ of school children and more or less $100 \%$ of adults have dental cavities. Generally chronic periodontal (base of teeth) disease, which may outcome in tooth loss. This is discovered in $1520 \%$ of middle-aged (35-44 years) men or women. by mouth being healthy problems in children and adults are higher among poor and unhelped group groups.

Public being healthy answers for by mouth being healthy issues are best when they are taken to be with to other does not get well diseases and with person public being healthy programs. The WHO complete of the mouth Health list of knowledge processing machine orders gave effect to work with the secret design of does not get well disease putting a stop to and being healthy given higher position.

The points of the paper are to represent the oral health problems on global aspect and to depict its significance in global health. Sources of the information are WHO dental health country or area profile program, WHO Oral Health Data Bank, and distinctive logical papers on oral health contemplate in different nations on the planet.

The oral health studies directed and recorded depended on broadly illustrative specimens, using either Pathfinder or random sampling system 2 . WHO standardized criteria are used for recording of oral diseases and trials are tested for quality control of data and evaluation of variability of results got. The WHO Global Oral Health Data Bank is as of now connected with the new data frameworks for observation of chronic disease and risk factors 2 . 
International Journal of Science and Research (IJSR)

ISSN (Online): 2319-7064

Index Copernicus Value (2016): 79.57 | Impact Factor (2015): 6.391

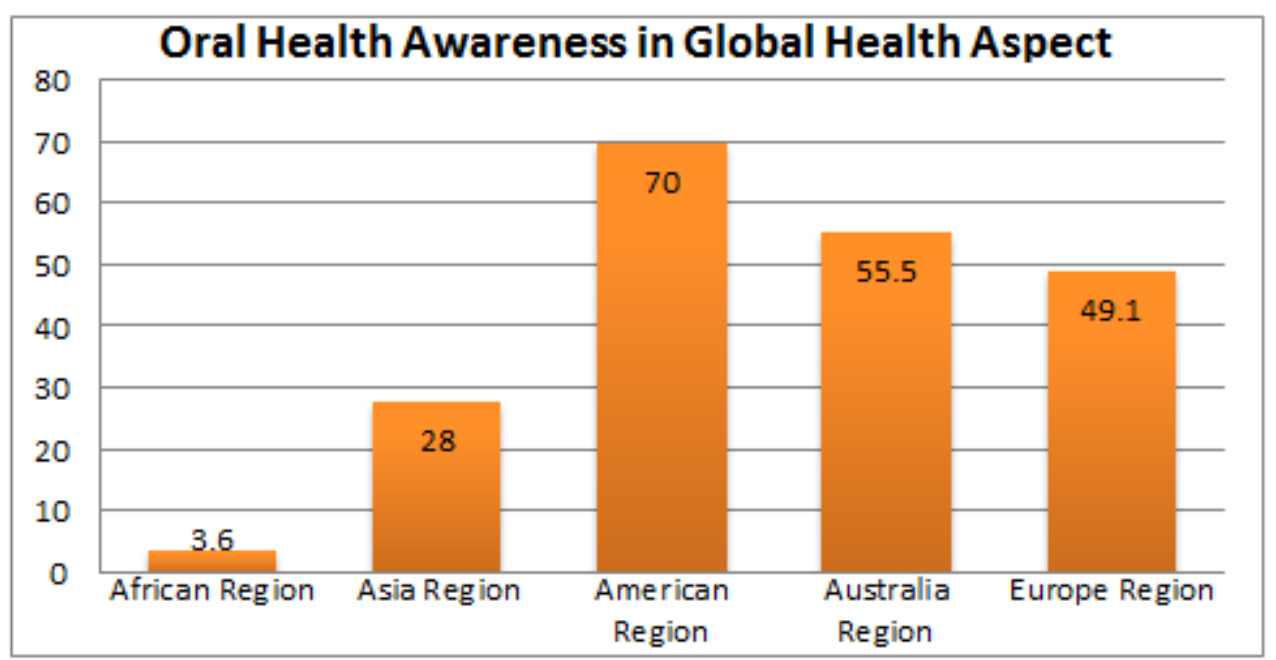

Figure 1: Current Statistics of Oral Health Awareness in Global Health aspects

Before calculation of the global oral health awareness status, we have categorized the awareness data from the various country's poor oral health reduction and a number of visits to a dentist for last one year.

\section{Global Burden of Dental Diseases}

The global most important oral burdens are considered to be the dental caries (tooth decay) and periodontal disease (gum disease). $60-90 \%$ of school age children and almost $100 \%$ of adults are affected by dental caries in the world 1 . At present, dental caries is widely spread in the globe and within the same region or country with different level of severity2.DMFT or missing, decayed and restored teeth index is a method to evaluate the severity of dental caries in permanent or succeedineous dentition. Currently, 1.86 is the average DMFT in 12 years old children in theworld. Figure 2 illustrates the rising of dental disease globally, comparing with the past disease records and difference in severity in various regions and countries.

In America DMFT of 2.08 in 12 year's old children is still high, though decreasing compared with the past years where DMFT was 2.35. recently a tremendous rise of DMFT from
1.87 to 2.97 in South East Asia, Indonesia, Jakarta and peripheral areas counting a DMFT of 3.2 and 2.3 in Nepal alone4. Eastern Mediterranean index is somewhat lower, while in African and Western Pacific regions dental caries is less severe5.

Most developing countries dental caries severity were low until recent years as demonstrated in time trends in dental caries affecting 12 years old children by the WHO global oral health data base. With lifestyle change and increased sugar consumptions, the prevalence rates rising rapidly with other crucially contributing factors like inadequate fluoride exposures, scarcity of oral health care providers and lack of public oral health promotion and oral disease prevention6.

However, over past 20 years, dental caries prevalence rates decreased in most developed countries has been noticed. This decline is interpreted to be from a number of implemented public health measures success coupled with improved living conditions and llifestyles 2 . But still, it must be emphasized that dental caries is not eliminated but controlled to some extents and all age groups are affected by this burden especially children.

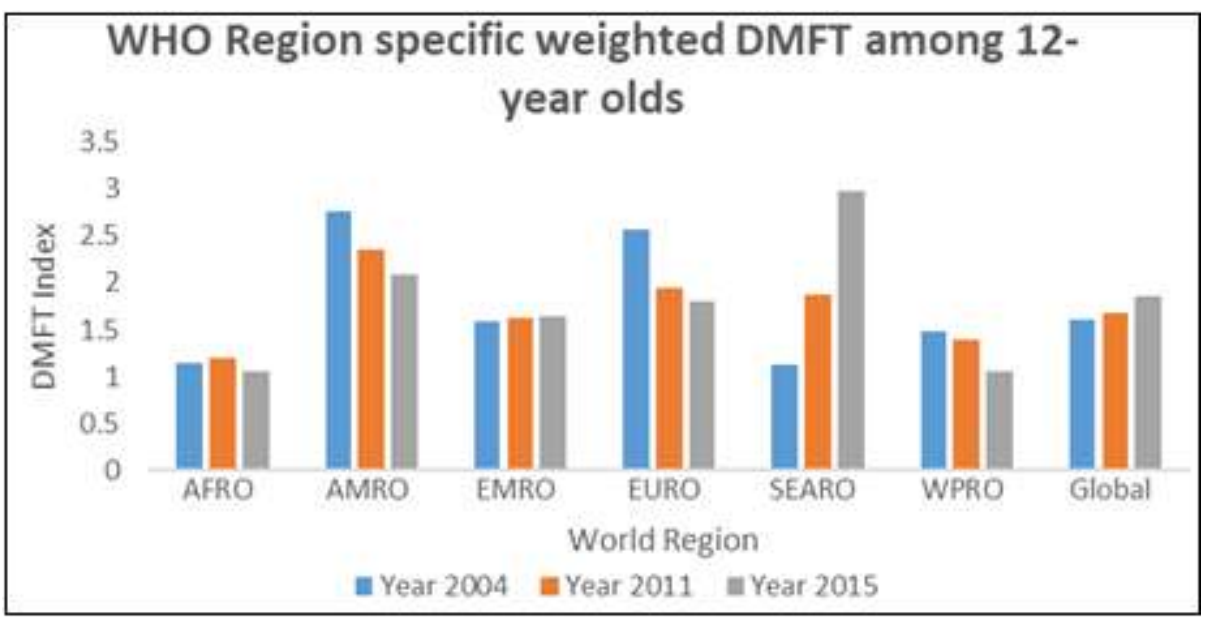

Figure 2: WHO Region specific weighted DMFT among 12 years olds

Globally, among adults' dental caries is high as almost $100 \%$ of the most countries population is affected by the disease 2 .
Most developed countries express high levels of DMFT index as at age of 35-44 years old on average 14 teeth are found to

\section{Volume 6 Issue 12, December 2017}




\section{International Journal of Science and Research (IJSR) \\ ISSN (Online): 2319-7064}

Index Copernicus Value (2016): 79.57 | Impact Factor (2015): 6.391

have dental caries, interestingly reports shows the rising of dental caries in several developing countries while the disease levels encountered used to be lower in those countries6. In several developed countries, reduced quality of life is often experienced by older people because of extracted teeth early in life due to pain and discomfort.

Despite some countries, 65 years or more aged adults edentulous proportion is still high, there have been a positive trend in reduction of toothless in most developed countries2. Preventive or restorative dental care is given little importance in developing countries where mostly oral health care services are offered from urban central hospitals6.The scarcity of oral health care providers in Africa where approximately 1:150 000 dentists to population, whereas in most developed countries is about 1:20006.

To relieve pain and discomfort, teeth are often left untreated in many children and adults affected by severe dental caries. The rise of impaired oral function and tooth loss is expected in several developing countries as public health issues. Periodontitis (gum disease) usually begins as gingivitis (chronic inflammation of gums) which is reversible in most patients.

If the offending stimulus is not removed, treated or subsided it progresses to periodontitis, a more genuine condition that destroys tooth-supporting tissues and bone. Around 15\% of the population, become edentulous that is rapidly driven by a serious advanced periodontitis7.1The disease is of major global oral health importance with huge socio-economic and health system impacts, as $15 \%$ of periodontitis is found in 35-44 years of age adults.

Periodontal diseases and dental caries principally cause tooth loss which significantly is the global burdening of oral disease component and is highlighted in world health survey (WHS). In developed countries prevalence rate of edentulous (tooth loss) is $35 \%$ higher compared to $10 \%$ in developing countries among 65-74 year-olds1. Remarkably, in recent years a positive reduction of edentulous in older people has been noticed in many of these countries.

Meanwhile, social disparities in edentulous are noted among older people with less education and low income1.

\section{Oral Mucosal Lesions and Oral Cancer}

Oral mucosal lesions are also considered potentially cancerous conditions (leukoplakia and erythroplakia). "A white patch firmly attached to the oral mucosa that cannot be classified as any other disease entity" is leukoplakia, the commonest form of oral potentially malignant lesion2.

Erythroplakia which are less common in people with $1 \%$ or less rate of prevalence, has more probability to malignant transformation than leukoplakia, they appear as red patches in the oral cavity 8 . Oral cancer is a genuine growing issue in several countries around the world. 6th commonest cancer together oral and pharyngeal cancers where around $90 \%$ are of squamous cell carcinoma type 9 .

The annual assessed incidence is around 275,000 and 130,000 for oral and pharyngeal cancers respectively, $66 \%$ of these cases seen in developing countries 9. For each 100,000 individuals, 1 to 10 cases range oral cancer incidence rate in most countries. Oral cancer prevalence rate is relatively higher in old people, mostly men and people with less education and low income, tobacco and alcohol consumptions are major risk factors 2 . Both incidence and prevalence cases of lip and oral cancers widely varies geographically.

High incidence rates of oral cancers including lips are seen in regions of Asia, Europe, Latin America and less in Africa and Oceania10. North America, Europe and Oceania shows high prevalence rates intercontinentally, Bangladesh lead in prevalence rates in countries 10 .

\section{Noma}

Noma (cancrumoris) is an opportunistic infection that develops rapidly from acute necrotizing ulcerative gingivitis (ANUG) and oral herpetic ulcers that spreads to orofacial tissue gangrene and destruction11. It occurs around the world, yet most commonly in sub-Saharan Africa.

The peak incidence of noma is 1-4 years of age, late phases of the disease occur in adolescents and adults2. 1998, 140,000 children estimated by QHO are affected by noma each year, $79 \%$ of them die from the disease and related sequelae around the world12. Complex interactions between malnutrition, infection, and suppressed immunity hugely contribute to noma12. 2003, in North Nigeria annual incidence of noma is 6.4 for every 1000 children and 25600 incidences for Sahara bordering countries 12 .

\section{HIV/AIDS and Oral Health:}

Oral symptoms are developed approximately $50 \%$ of people living with HIV mostly in beginning of the disease course, caused by fungal, bacterial and viral infections13.Severe periodontitis, pseudomembranous oral candidiasis, hairy leukoplakia, xerostomia, lymphoma and Kaposi sarcoma are oral diseases strongly related to HIV infection2.

All these conditions have significant negative impacts on quality of life because of difficulty in chewing, swallowing, speaking and food taste that are due to pain and discomfort. Xerostomia (dry mouth) as results of reduced salivation is an aggravating factor it leads to dental caries and other opportunistic infections 2. Obstruction to seek dental care was shown in a prospective observational study that cost is $30 \%, 19 \%$ fear, and low motivation $13 \%$.

$65 \%$ of HIV positive patients had un-achieved dental care in past years 14. There is a great need for oral healthcare services among the disadvantaged groups of people and people living with HIV/AIDS.

\section{Congenital anomalies}

Inherent abnormalities represent a stunning 25.338.8 million dalys through being available in all countries. dalys are a well set up metric for measuring the weighting of sickness regarding both passing rate and rate of malady; 1 DALY is 1 solid year of living lost due to, in connection to Incapacity or

\section{Volume 6 Issue 12, December 2017}




\section{International Journal of Science and Research (IJSR) \\ ISSN (Online): 2319-7064 \\ Index Copernicus Value (2016): 79.57 | Impact Factor (2015): 6.391}

once in a while by early demise. The WHO close-by entire weighting of sickness work-put go to individual in expert says that appearing blunders degree seventeenth in reasons for ailment weighting.

More often than not isolated lip and feeling of taste (CLP) is around 1 of every 700 live births, making CLP the most widely recognized orofacial conceived with advancement aggravations. Influenced patients endure a multidimensional issues and concentrating on the useful and magnificence related issues of CLP is particularly testing.

CLP is a most normal assortment of teeth-related irregularity, which additionally have a long haul impact on the patient's facial life structures and fearlessness. Customary features of CLP patients are various missing teeth/hypodontia/agenesis (generally the maxillary sidelong incisors), ectopic teeth, impaction, supernumerary teeth, microdontia, and maxillary canines and premolars transposition.

Regularly put off progression of crown and root and twisting and various spoiled teeth.

\section{Oral trauma}

Information from the majority of the nations demonstrated that $1 / 3$ rd of all preschool youngsters have endured awful dental wounds including the essential dentition.

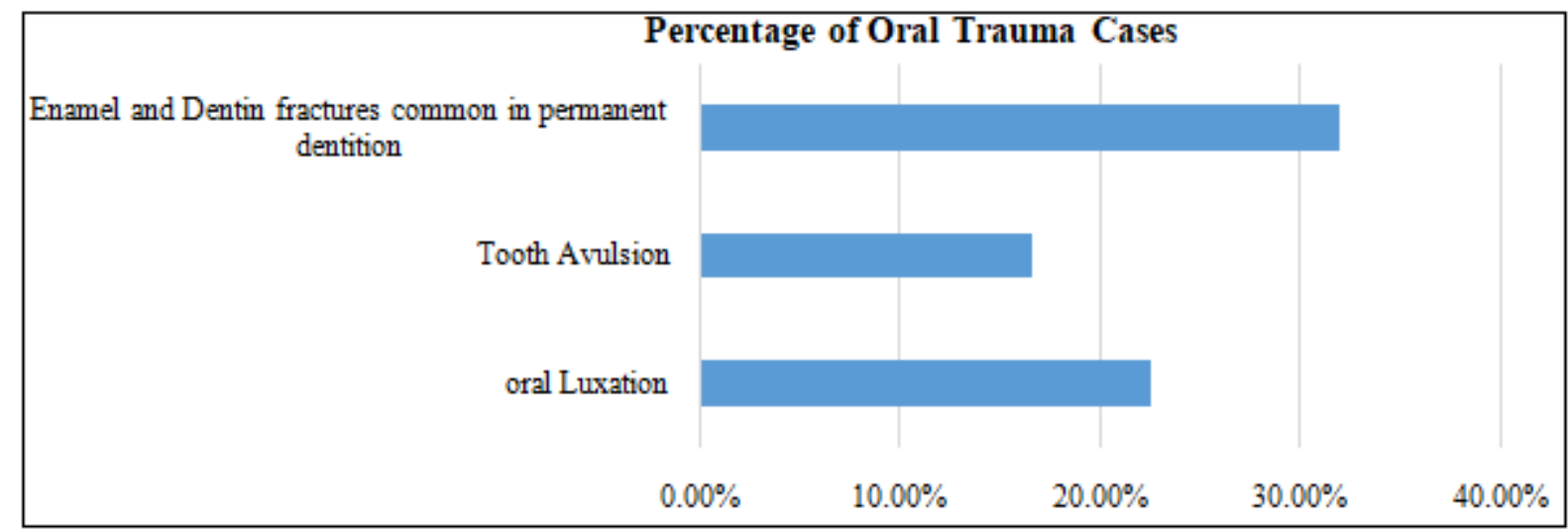

Figure 3: Percentage of Oral Trauma cases globally

Most regular dental wounds in lasting and essential dentitions include the foremost teeth of the upper jaw, particularly the maxillary focal and sidelong incisors.

Awful dental wounds for the most part influence a solitary tooth, yet certain injury occasions, for example, financial, political, and auto collisions result in numerous tooth wounds. Most basic reasons for perpetual dentition injury are games and street movement damage. Concentrates from certain industrialized nations have uncovered that the aversion of dental horrendous wounds is on the expansion, running from $16 \%$ to $40 \%$ among 6 years of age youngsters and from $4 \%$ to $33 \%$ among 12-14-year-old kids.
Oral diseases and risks factors:

Oral wellbeing ailments are identified with various hazard components and determinants. The greater part of the hazard factoris identified with numerous perpetual sicknesses, as cardiovascular infections, tumor, interminable respiratory maladies, and diabetes. Significant hazard factors are tobacco biting, Smoking, high sugar admission, and liquor utilization.

Once in a while determinant like financial status likewise impact oral wellbeing with general wellbeing. In this way, the way to deal with diminishing and keeping these dangers won't just enhance oral wellbeing however will likewise vastly affect the worldwide weight of NCDs, wellbeing frameworks, and general improvement advance.

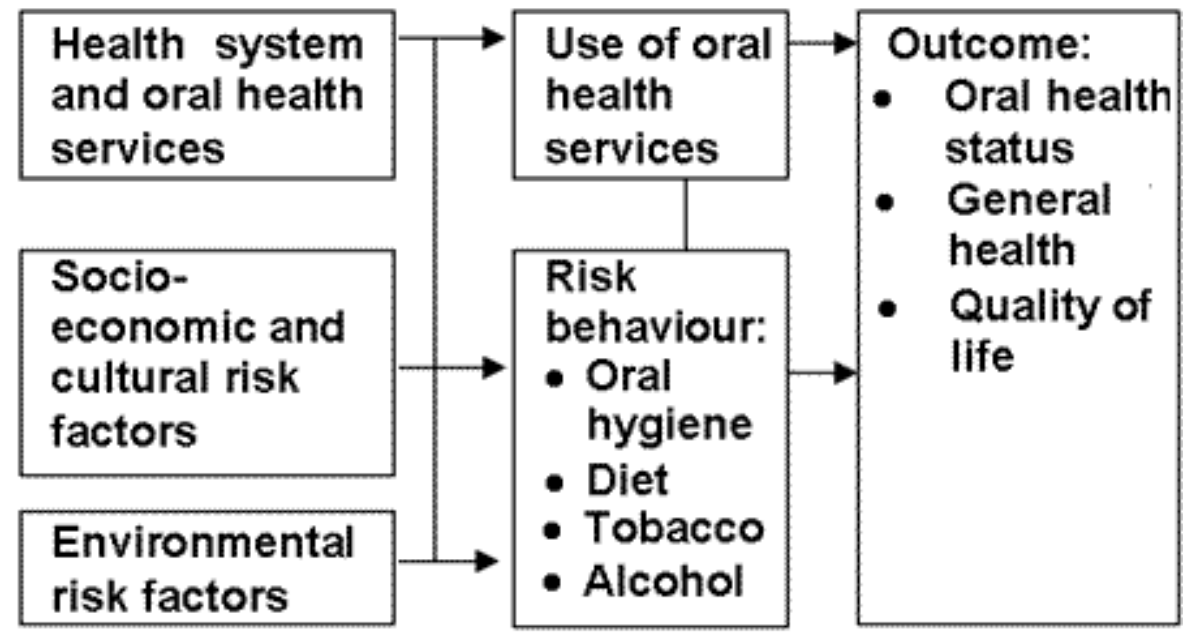

Figure 4: Common Risk Factor Approach (adapted from WHO, Petersen, 2003)

Volume 6 Issue 12, December 2017 www.ijsr.net 


\section{International Journal of Science and Research (IJSR) \\ ISSN (Online): 2319-7064 \\ Index Copernicus Value (2016): 79.57 | Impact Factor (2015): 6.391}

Economic impact of oral health

Regardless of the greatness of oral infections and their fundamental linkages with different ailments, oral wellbeing is generally ignored in the political improvement field. This wide separation between the universal wellbeing talk and the zone of worldwide oral wellbeing is identified with an arrangement of complex fundamental issues.

In spite of the fact that the great part of the oral ailments are preventable and everybody will probably be influenced amid the lifetime. Oral maladies significantly affect the personal satisfaction. Their cooperation in the public arena and financial efficiency and in addition on wellbeing frameworks, making oral infections a noteworthy general wellbeing concern.

The WHO assesses that they are the fourth costliest condition to treat. It's a corrective approach, as opposed to concentrating on the avoidance. The consumption on dental care as a level of aggregate wellbeing use is frequently lower than $6 \%$, which can go as low as $0.5 \%$ in Mongolia contrasted with $8 \%$ in the Unified States (which spent more than \$ 100 billion on oral social insurance in 2009).

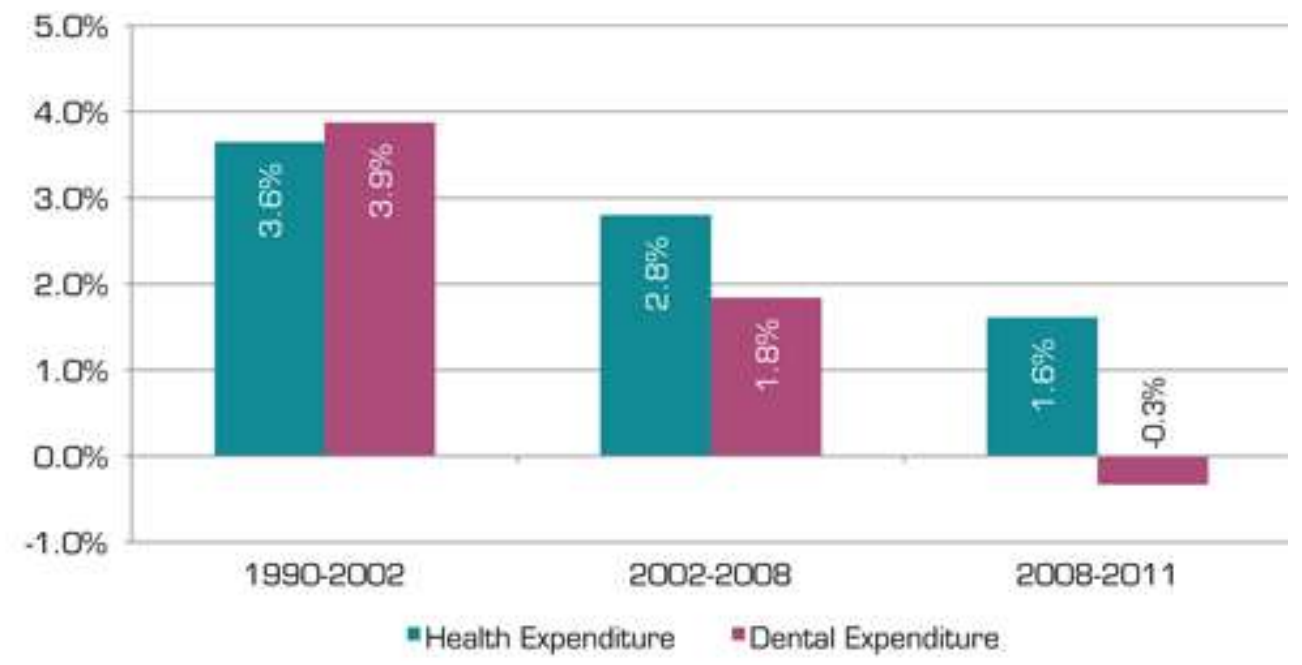

Sources: Vujcic M. Dental Spending Flar Since 2008, Began to Stow in 2002. Heath Policy Resources Center Research Brief. American Dental Association. March 2013

Figure 5: Average Expenditure in Health \& Dental

\section{Prevention of oral diseases}

Individuals all-inclusive have been prohibited from the advantages of financial advancement and the logical advances which have enhanced human services and personal satisfaction. The social, monetary, social, and social which decides the wellbeing which is noteworthy Better wellbeing can be accomplished by diminishing neediness.

By and large, wellbeing frameworks, including oral wellbeing frameworks, have parts to play. Frameworks are ending up more unpredictable and individuals' desires of social insurance are rising significantly. WHO's goals are to make healthiest populations and communities. Four strategic directions provide the broad framework for focusing WHO's technical work.

Reducing the burdening of oral health disease in the poor and marginalized population. Promotion of healthy lifestyle, reducing the risk factor. Health system for oral health should be equitably improved outcome and should fulfill people's needs. Implementation of oral health policy in all country based on the other national level health programs.

\section{Global Oral Health Goal 2020:}

Promotion of oral health Minimizing the impact of disease related to oral health and craniofacial region. Early diagnosis and prevention of severe oral diseases Decrease the burdening of oral health disease from current status.

\section{Conclusion}

Oral diseases are a noteworthy global health burden as it affects all region of the world. The impact on individuals or communities is of concern as consequence of pain, impaired or loss of function decreased the quality of life and socio-economical affect. Globally, the disadvantaged and poor population groups have greatest oral diseases burdens. Oral health is still economically neglected in most health systems globally. The current oral diseases pattern illustrates the risk profile crosswise over various countries in relation to lifestyle, living conditions, environmental factors and preventive measures implementation.

In a few created nations there has been a positive variable in the decrease of dental caries in kids and tooth misfortune in more established populace however dental caries in youngsters has not been annihilated, in spite of the way that it has been brought under control in some created nations. The older population is still suffering from the burdens of oral diseases and this brings about a reduced quality of life.

Oral health awareness and prevention programmes are still scarce several developing countries. Due to increase in consumption of sugar and low exposure to fluorides, it is predicated that dental caries will rise up as already shown by a tremendous rise in dental caries in SEARO (South East Asia Region). 


\section{International Journal of Science and Research (IJSR) \\ ISSN (Online): 2319-7064}

Index Copernicus Value (2016): 79.57 | Impact Factor (2015): 6.391

The developing of tobacco utilization in creating nations danger of periodontal ailments, tooth misfortune and oral disease will increment. The periodontal infections and tooth misfortune are emphatically connected to endless ailments like diabetes mellitus, the high danger of diabetes will negatively affect oral wellbeing in a few areas of the world.

Therefore, global emphasis on public health programmes on implementing oral health promotion and oral diseases prevention is of urgent need and social determinants of health and risk factors integration in oral health with global health programmes.

\section{References}

[1] " ORAL HEALTH AWARENESS AND PRACTICES OF PRIMARY SCHOOL TEACHERS IN IBADAN, NIGERIA" by FB Lawal $₫$ and OO Bankole, 2014 Apr-Jun; 4(2): 47-65

[2] "Status of oral health awareness in Indian children as compared to Western children: A thought-provoking situation (A pilot study)", by Navneet Grewal, Manpreet Kaur, Year: 25 | Volume Issue: Issue Issue:Page: $15-19$

[3] AIHW Dental Statistics and Research Unit Research Report No. 45, Oral health behaviors in the Australian population 2004-06

[4] The World Oral Health Report, 2003,Poul Erik Petersen ADA News, Survey finds shortcomings in oral health habits, October 20, 2014

[5] Enwonwu, C. O., Falkler, W. A., \& Phillips, R. S. (2006). Noma (cancrumoris). The Lancet, 368(9530), 147-156.

[6] Petersen, P. E., Bourgeois, D., Ogawa, H., Estupinan-Day, S., \&Ndiaye, C. (2005). The global burden of oral diseases and risks to oral health. Bulletin of the World Health Organization, 83(9), 661-669

[7] Warnakulasuriya, S. (2009). Global epidemiology of oral and oropharyngeal cancer. Oral Oncology, 45(4), 309-316.

[8] "Congenital Anomalies in Low- and Middle-Income Countries: The Unborn Child of Global Surgery",Nicole A. Sitkin, $\triangle$ DorukOzgediz, Peter Donkor, and Diana L. Farmer, 2014 Aug 19. doi: 10.1007/s00268-014-2714-9

[9] Mossey P, Castilla E. Geneva (CH): World Health Organization; 2003. Global Registry and Database on Craniofacial Anomalies.

[10] "Common Dental Anomalies in Cleft Lip and Palate Patients",Sanjida HAQUE and Mohammad KhursheedALAM, 2015 Mar-Apr; 22(2): 55-60.

[11] "Traumatic dental injuries: etiology, prevalence, and possible outcomes", health" By Zaleckiene, VytautePeciuliene, VilmaBrukiene, SauliusDrukteinis, Baltic Dental and Maxillofacial Journal, 16: 7-14, 2014

[12] 2005 Sep; 83(9):661-9. Epub 2005 Sep 30. “ The global burden of oral diseases and risks to oral health" By Petersen PE1, Bourgeois D, Ogawa H, Estupinan-Day $\underline{S}$, Ndiaye C.

[13] WHO Oral health. WHO. 2016. http://www.who.int/mediacentre/factsheets/fs318/en/.

[14] Petersen PE BD Ogawa H, Estupinan-Day S and Ndiaye C. The Global burden of oral disease and risks to oral health. Bull World Health Organ. 2005;022806(05):661-669. doi:10.1590/S0042-96862005000900011.

[15] Global DMFT for 12-year-olds: 2015. 2012. http://www.mah.se/CAPP/Country-Oral-Health-Profile s/According-to-Alphabetical/Global-DMFT-for-12-yea r-olds-2011/.

[16] SEARO. /CAPP/Country-Oral-Health-Profiles/SEARO/.

Published September 8, 2010. Accessed September 19, 2017.

[17] Global DMFT for 12-year-olds: 2015. /CAPP/Country-Oral-Health-Profiles/According-to-Al phabetical/Global-DMFT-for-12-year-olds-2011/. Published February 14, 2012. Accessed September 19, 2017.

[18] World Health Organization. Future Use of Materials for Dental Restoration. 2009:65-65.

[19] Allen CM, Camisa C. Oral Disease.; 2015. doi:10.1038/npg.els.0002133.

[20] Petersen PE, Bourgeois D, Ogawa H, Estupinan-Day S, Ndiaye C. The global burden of oral diseases and risks to oral health. Bull World Health Organ. 2005;83(9):661-669. doi:10.1590/s0042-96862005000900011.

[21] Warnakulasuriya S. Global epidemiology of oral and oropharyngeal cancer. Oral Oncol. 2009;45(4-5):309-316. doi:10.1016/j.oraloncology.2008.06.002.

[22] WHO | Global data on the incidence of oral cancer (maps). WHO. 2016. http://www.who.int/oral_health/publications/cancer_m aps/en/.

[23] Enwonwu CO, Jr WAF, Phillips RS. Noma ( cancrumoris ). 2006;368:147-156.

[24] Enwonwu CO, Falkler WA, Idigbe EO. Oro-Facial Gangrene (Noma/Cancrum Oris): Pathogenetic Mechanisms. Crit Rev Oral Biol Med. 2000;11(2):159-171. doi:10.1177/10454411000110020201.

\section{Volume 6 Issue 12, December 2017}

